\title{
Treatment Seeking Behavior and the Profile of Infertile Patients Attending the Tertiary Infertility Center at Dhaka
}

\author{
PFATIMA $^{\mathrm{a}}$, MM HOSSAIN ${ }^{\mathrm{b}}$, D RAHMAN ${ }^{\mathrm{c}}$, HB HOSSAIN ${ }^{\mathrm{d}}$, HN HOSSAIN ${ }^{\mathrm{e}}$, FA HOSSAIN ${ }^{\mathrm{f}}$, CYNTHIA $^{\mathrm{g}}$
}

\begin{abstract}
Summary:
Background: Motherhood is an integral part of womanhood and being childless is a devastating experience for a woman in developing countries like Bangladesh. Majority of patients in developing countries have virtually no access to treatment. Few health facilities have provision for proper diagnosis and treatment for infertility. There is a general lack of awareness among the public regarding infertility. In the quest for conception, many couples adopt for alternative therapies and religious rituals killing crucial age and time.

Objective: To find out the treatment seeking behavior and the profile of infertile patients attending a tertiary infertility center at Dhaka, Bangladesh .
\end{abstract}

Methods: During a period of five years from January 2001 to December 2005, 8580 new patients attending a tertiary infertility center at Dhaka were included in the study.

Results: Treatment seeking behavior of infertile patients attending Center for Assisted Reproduction, (CARe) Dhaka revealed $30 \%$ of the patients initially go to the traditional healers for the relief of infertility, $36 \%$ consult both traditional healers and doctors and $32 \%$ consulted with GP and Gynae specialist, and only $2 \%$ came straight to the tertiary center( CARe) for their subfertility. $55 \%$ of the patients attending the clinic were from urban area and $45 \%$ were from rural area. The maximum number of patients were from Dhaka division followed by Chittagong, Khulna,

Introduction:

Access to adequate comprehensive reproductive health services, including infertility care, is a basic reproductive

a. Prof. Parveen Fatima, Professor (Infertility), BSMMU.

b. Prof. Mohammad Moazzam Hossain, Professor \& Chief Embryologist, Centre for Assisted Reproduction.

c. Dr. Dilruba Rahman, Co-ordinator IVF, Centre for Assisted Reproduction.

d. Dr. Humayra Bushra Hossain, Medical Officer, Centre for Assisted Reproduction.

e. Dr. Humayra Nawrin Hossain, Medical Officer, Centre for Assisted Reproduction.

f. Dr. Fahim Abrar Hossain, Medical Officer, Centre for Assisted Reproduction.

g. Dr. Cynthia, Medical Officer, Centre for Assisted Reproduction.

Address of Correspondence: Prof. Parveen Fatima, Centre for Assisted Reproduction, 2/1-A, Iqbal Road, Mohammadpur, Dhaka-1207, Bangladesh. e-mail: drpfatima@gmail.com

Received: 1 June, 2015

Accepted: 29 June, 2016
Barisal, Sylhet and Rajshahi. The overall primary and secondary infertility were in $63.34 \%$ and $36.66 \%$ of the patients respectively. $90 \%$ of the patients were Muslim and 9\% were Hindu and 1\% were from other religion. Only $32.37 \%$ of the patients took treatment in the clinic for their infertility. Male factor problems as identified among the male partners of the infertile couples were azoospermia in $18 \%$, abnormal semen parameter in $24 \%$, and normal semen parameter in $58 \%$. Among the female partners completing investigations, $17 \%$ suffered from anovulation, $20 \%$ from premature ovarian failure and 3\% from ovarian failure , with a total of $40 \%$ of the women suffering from ovarian factor, $8 \%$ suffered from endometriosis, $7 \%$ from bilateral tubal block, 3\% from uterine factor problem. In $42 \%$ women there was no apparent cause in the females. Untreatable causes of infertility among the infertile couples were in $3.75 \%$ of the patients. Ovarian failure was in 3\% cases, testicular failure in $0.5 \%$ and uterine factor in $0.25 \%$ of cases. $75 \%$ of the women were less than thirty five years of age where as $29 \%$ of the males were less than 35 years.

Conclusion: Causes of infertility vary from region to region so also social and cultural conditions. Financial condition also affects the health seeking behavior of the patients. For the purpose of management of infertile couples the cause of infertility is important to understand so that the options of treatment and the prognosis can be discussed with the patients.

(J Bangladesh Coll Phys Surg 2016; 34: 140-144)

right. Women go through various treatment-seeking modes to avoid the adverse consequences of childlessness. We wanted to find out the health-seeking behavior of infertile patients and the major causes of infertility in patients attending a tertiary infertility center at Dhaka, Bangladesh . Since the last 12 years tertiary infertility center facility is available in Bangladesh. Awareness on infertility management and the information that infertility is treatable and the treatment is available in the country is being focused by the physicians and the print and other medias. $8-10 \%$ of the reproductive age group couples suffer from infertility affecting some $50-80$ million people ${ }^{1}$. In countries with poor health care facilities infertility rates are also highest. Majority of the infertile couples blame their fate for infertility. A significant part of infertile couples seek treatment from improper place for their infertility. 'Helping Families' is a fertility survey endorsed by the Indian Society for Assisted Reproduction (ISAR), the 
Asia-Pacific Initiative on Reproduction (ASPIRE) and according to their survey $64 \%$ of the couples studied believed in God's will and delayed treatment. Seeking help can take many forms and is not restricted exclusively to medical services, and their long waiting can impede success infertility treatment by loosing crucial age and time. It is important to know the health seeking behavior of the patients, the etiologic factors for the proper prevention and management of the patients and to plan the health care facilities according to the demand of the patients. Local healers in the informal sector were found to be the most popular health service option among the rural childless women. The factors for utilizing them included low costs, the gender of the provider (with same-sex providers being preferred), having a shared explanatory model with the healers, and easy availability. However, despite their affiliation with modern treatment, urban childless women still believe, like their rural counterparts, that the remedy for childlessness ultimately depends on God. As a result, in addition to biomedical treatment, many return to or simultaneously pursue various traditional, spiritual or folk treatments.

\section{Results:}

During a period of five years from 2001 to 2005, 8580 new patients was enrolled in Center for Assisted Reproduction, (CARe), a tertiary infertility center in Dhaka, Bangladesh (Fig:1). Health seeking behavior of

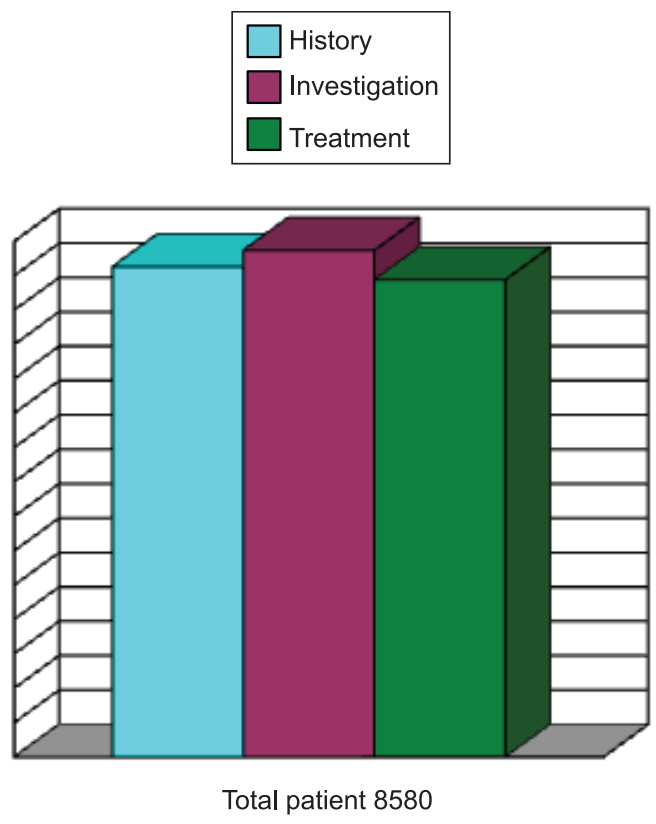

Fiig.-1: Patient attending CARe - IVF during 2001 2005. infertile patients attending the outdoor of Center for Assisted Reproduction, (CARe) Dhaka, Bangladesh revealed $30 \%$ of the patients initially went to the traditional healers for the relief of infertility, 36\% consulted both traditional healers and doctors and 32\% consulted with GP and Gynae specialists, and only 2\% came straight to the tertiary center (CARe) for their subfertility. Among the patients attending the clinic $33.25 \%$ gave only one visit, when a complete history, physical examination and recording of the previous investigations done by the patients was recorded. 34.37 $\%$ of the patients completed the investigations required for their evaluations and only $32.37 \%$ took treatment in the center for their infertility.

The overall primary and secondary infertility was in $63.34 \%$ and $36.66 \%$ of the patients respectively. Among the patients giving only one visit $56 \%$ were suffering from primary infertility and $43.5 \%$ suffered from secondary infertility, among the patients completing investigation $68.5 \%$ and $31.5 \%$ suffered from primary and secondary infertility, whereas $65 \%$ and $35 \%$ of the patients taking treatment in the clinic suffered from primary and secondary infertility respectively (Fig:2). The maximum patients were from Dhaka division followed by Chittagong, Sylhet, Rajshahi, Khulna and Barisal (Fig:3). Patients taking treatment were mostly from Dhaka division. Male factor problems as identified were azoospermia, abnormal semen parameter, normozoospermia in the patients attending the clinic

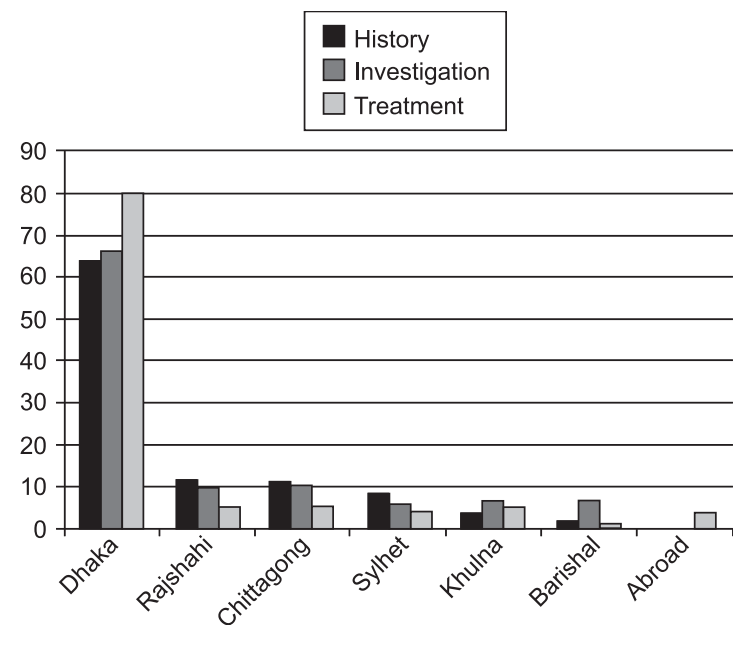

Fig.-2: Distributions of Patients attending CARe-IVF from to different divisions of Bangladesh. 
were in $18 \%, 24 \%$, and $58 \%$ repectively. In patients completing investigations $17 \%$ suffered from anovulation, $23 \%$ from premature ovarian failure and ovarian failure, $8 \%$ suffered from endometriosis, $7 \%$ from bilateral tubal block, $3 \%$ uterine factor problem and $42 \%$ had no apparent problem. Untreatable causes of infertility were in $3.75 \%$ of the patients , ovarian factor was in $3 \%$ cases, testicular failure in $0.5 \%$ cases and uterine factor in $0.25 \%$ of cases. In $42 \%$ women there was no apparent cause.

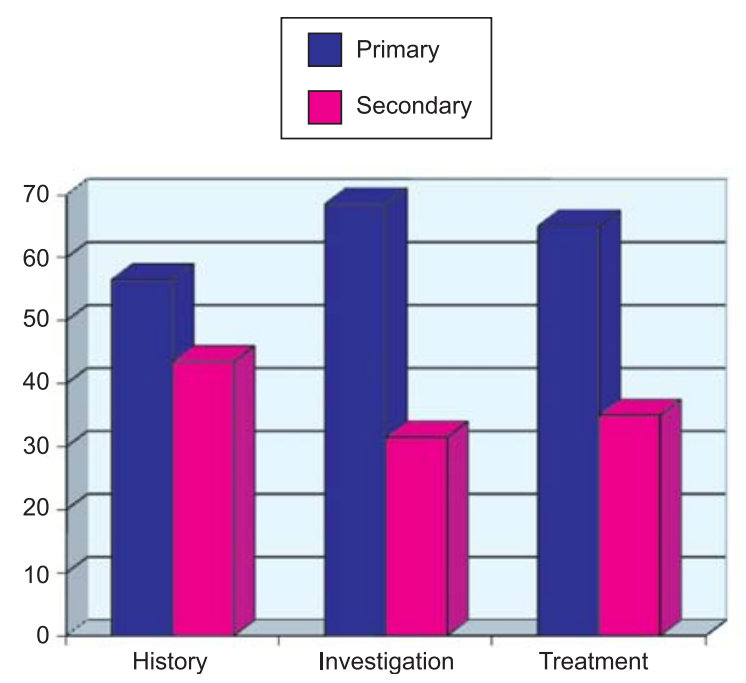

Fig.-3: Type of Infertility

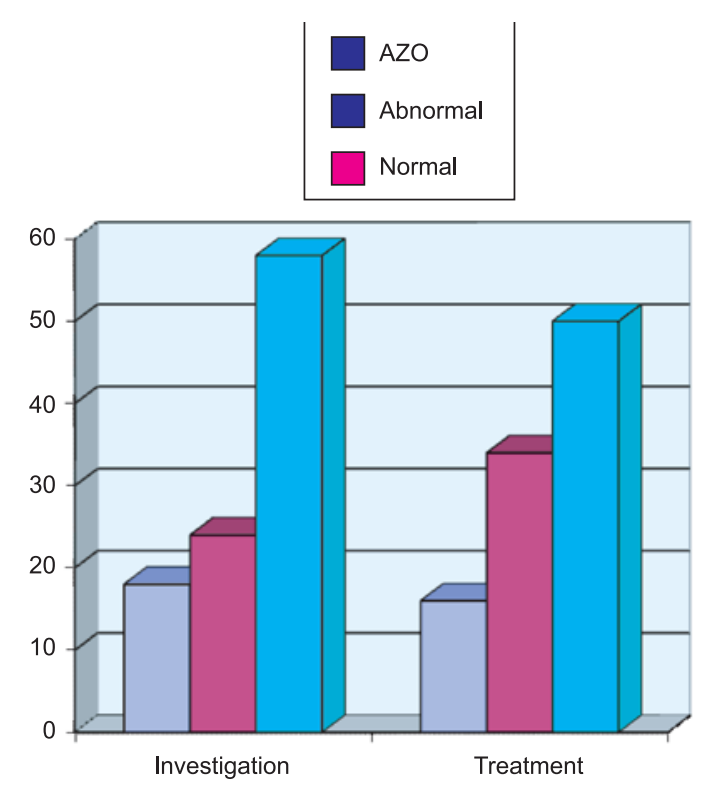

Fig.-4: Male Factor in CARe-IVF

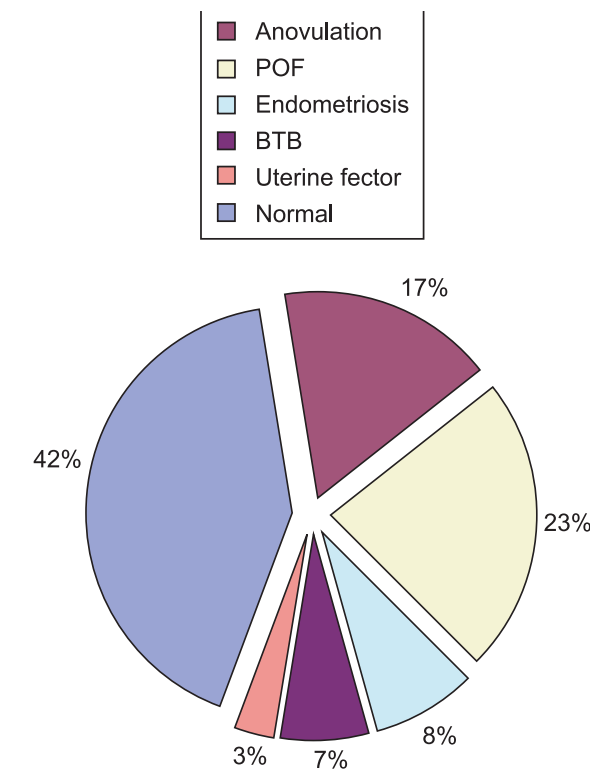

Fig.5: Female factor in patients undergoing investigations only.

\section{Discussion:}

The principal objectives of this study are to improve our understanding of infertility patients' patterns of health seeking behavior and their patterns of access to infertility treatment. Treatment seeking behavior showed that $30 \%$ of the patients initially went to the traditional healers for the relief of infertility, 36\% consulted both traditional healers and doctors and 32\% consulted with GP and Gynae specialist, and only 2\% came straight to the tertiary center( CARe) for their subfertility. One study showed that the delay in seeking assistance may be due to poor knowledge of infertility, unavailable and/or inaccessibility of appropriate services, prior unsuccessful medical intervention and previous visits to traditional healers. ${ }^{[2]}$. In another study, infertile couple seek help from native doctors and prayer groups rather than orthodox Medicare. This was observed in this study where $65.1 \%$ had previously used traditional medications. ${ }^{3}$

Subfertile couples consulting fertility clinics are commonly regarded as highly motivated to achieve conception ${ }^{4}$. Bangladesh is an economically constrain country; almost one third of our patients desiring children give only one visit where as one third of the patients complete investigation and confirm the cause of infertility and almost one third come for treatment. This high drop out is also reported in different studies 
in developed countries. In Sweden where IVF cycles were fully reimbursed, $65 \%$ of couples did not complete the full treatment program of three IVF cycles ${ }^{5}$. Only $32.37 \%$ of the patients took treatment in the clinic for their infertility which is almost similar to that observed in other developed countries. Demand and the availability of infertility services in the United States increased during the 1980s and early 1990s. Of the 6.7 million women with fertility problems in 1995, 42\% had received some form of infertility services. The most common services received among these women were advice in $60 \%$ and diagnostic tests $50 \%$, medical help to prevent miscarriage $44 \%$ and drugs to induce ovulation in $35 \%{ }^{6}$. Another study showed approximately only $44 \%$ of women with infertility sought medical assistance which is comparable to our study. ${ }^{7}$

The percentage of secondary infertility is lowest in Asia and in developed countries; $23 \%$ and 29\%, respectively ${ }^{8,9}$. In our study the overall secondary infertility was $36.6 \%$ which is higher than the other studies in Asia. In the so-called "infertility belt" of SubSaharan Africa, the percentage of couples with secondary infertility exceeds $30 \%$ in some countries ${ }^{10}$. A study done in Mongolia showed that $43.7 \%$ of women had secondary infertility ${ }^{11}$. One study showed that $66 \%$ had primary infertility and $34 \%$ secondary infertility and in another study done in Dhaka primary and secondary infertility were $56 \%$ and $44 \%$ which is similar to our study $^{12,15}$. In a study in North West Nigeria Primary infertility constituted $32.8 \%$, while secondary infertility was $67.2 \%$ which is significantly higher than in our study ${ }^{3}$. Belsey suggested that a higher rate of secondary infertility, compared to primary infertility, could be used as a crude indicator of the possible effects of post abortal and post partum infection ${ }^{13}$.

In our study male factor problems as identified were azoospermia in $18 \%$, abnormal semen parameter in $24 \%$ and normozoospermia in $58 \%$ whereas in a study in Mongolia azoospermia was found in $20.5 \%$ cases , abnormal semen parameter in $23.9 \%$ and normozoospermia in 55.6\% attending the clinic ${ }^{1,4}$. In our study bilateral tubal block was in $7 \%$ of the infertile women where as in a study in Nigeria tubal occlusion was in $16.9 \%{ }^{14}$ and bilateral tubal blockage in $15.6 \%$ and $28.9 \%$ of the infertile women ${ }^{15,3}$ which are quite high than our series. Anovulation was in $17 \%$ in our study and $22.3 \%{ }^{16}$ in other study. In another study in
Bangladesh endometriosis was in $11 \%{ }^{17}$ where as in our study, $8 \%$ was diagnosed as endometriosis.

\section{Conclusion:}

Causes of infertility vary from region to region so also social and cultural conditions Financial condition also affects the health seeking behavior of the patients. Care for infertility in developing countries is as important as fertility control. As infertility usually does not cause any physical disability, little attention is paid at the national level. Childbearing and family are considered a right of every human being. Infertility is a public health problem that requires appropriate diagnosis and determinants. In developing countries, reproductive tract infections, including sexually transmitted diseases, complications of unsafe abortions, and puerperal pelvic infections are regarded as important causes of infertility. Proper awareness and education of the patients and medical professionals and safe and efficient treatment facility are the key factors to protect this basic right of the patient.

\section{References:}

1. World Health Organization. Infertility: a tabulation of available data on prevalence of primary and secondary infertility. Geneva, WHO, Programme on Maternal and Child Health and Family Planning, Division of Family Health, 1991.

2. Bala M Audu, Aifred A. Massa, Muhammad Buker : Clinical presentation of Infertility in Gombe, North Eastern Nigeria. Trop J Obstet Gynecol 2003 ; 20 : 93-96

3. Panti AA,Sununu YT. The Profile of infertility in a teaching Hospital in North West Nigeria.2014;17(1):7-11

4. Domar AD: Impact of psychological factors on drop-out rates in insured infertility patients. Fertil Steril 2004; 81: 271-273.

5. Olivius C, Friden B, Borg G, Bergh C: Why do couples discontinue in vitro fertilization treatment? A cohort study. Fertil Steril 2004; 81: 258-261.

6. Stephen EH,Chandra a. Use of Infertility Services in the United States: 1990 Family Planning Perspectives. 2000;32(3):

7. Infertility As A Covered Benefit, William M. Mercer, 1997) World Health Organization (WHO) and the American College of Obstetricians and Gynecologists (ACOG) recognize infertility as a disease

8. Larsen U. Primary and secondary infertility in subSaharan Africa. Int J Epidemiol 2000; 29: 285-291.3.

9. Cates W, Farley TM, Rowe PJ. Worldwide patterns of infertility: Is Africa different? Lancet 1985; 2:596-598. 
10. World Health Organization, Incidence and Prevalence Data, "628.9 Infertility of Unspecified Origin (General Comments),” Capitola, First Quarter (2011), 1-22,

11. Bayasgalan et al. Clinical patterns and major causes of infertility in Mongolia. J. Obstet. Gynaecol. Res. 2004; 30(5):386-393.

12. Menuba IE, Ugwu EO, Obi SN, Lawani LO, Onwuka CI. Clinical presentation of infertility in an outpatient clinic of a resource poor setting, South East Nigeria. Int J Trop Disease and Health 2012;2:123-31

13. Besley. WHO Report: The epidemiology of infertility. A review with particular reference to sub-Saharan Africa. Bull WHO 1976; 54: 319 - 345.

14. Bayasgalan G', Naranbat D', Amarjargal O', Radnaabazar J, Lhagvasuren V, Rowe PJ. Risk factors of Male Infertility in Mongolian men. Mongolian Journal of Health Sciences 2004; 2pp 1-7.
15. Chowdhury MA, Haque MM, Chowdhury S, Prodhania MS. Determinants of Infertility Among Couples Seeking Treatment in A Selected Clinic in Dhaka City. Chattagram Maa-O-Shishu Hospital Medical College Journal $2014 ; 13(3)$

16. Obuna JA, Ndukwe EO, Ugboma HA, Ejikeme BN, Ugboma EW. Clinical presentation of infertilityin an out patient clinic of a resource poor setting, South East Nigeria. Int J Trop Disease and Health 2012;2:123-31

17. Anwar BR, Fatima P, Afza N, Trannum T, Kulsum Su, Parveen S. Etiologic Factors of Infertility in a Referral Hospital (Bangladesh Journal of Medicine. 2013; 14(2)

18. B R Anwar, P Fatima, N Afza, T Tarannum, N Begum, S U Kulsum, S Parveen Etiologic Factors of Infertility in a Referral Hospital (BSMMU, Bangladesh Journal of Medicine, 2013 Vol 14, No 2 